\title{
Foliar, Fruit, and Soil-Applied Organic Insecticides for Oriental Fruit Fly, Bactrocera dorsalis (Diptera: Tephritidae), in Senegalese Mangoes
}

\author{
Assa Balayara, ${ }^{1}$ Carlyle C. Brewster, ${ }^{2}$ Larry J. Vaughan, ${ }^{3}$ and Douglas G. Pfeiffer ${ }^{4,+}$ \\ ${ }^{1}$ Universite Cheikh Anta Diop de Dakar/Ministère de l'Agriculture et de l'Equipement Rural, Direction de la Protection des Végétaux, BP:20054, \\ Thiaroye, Dakar, Sénégal \\ ${ }^{2}$ Department of Plant and Environmental Sciences, Clemson University, Clemson, SC 29634 \\ ${ }^{3}$ Center for International Research, Education and Development, Virginia Tech, Blacksburg, VA 24061 \\ ${ }^{4}$ Department of Entomology, Virginia Tech, Blacksburg, VA 24061
}

Accepted 16 July 2019. Published 20 August 2019.

\section{Abstract}

Since its invasion in Senegal (West Africa) in 2004, Bactrocera dorsalis Hendel, the oriental fruit fly, has caused loss of production of mango and other commercial fruits. The use of neem products (oil, cake, and seed powder) and kaolin may be an alternative to synthetic insecticides for controlling adult flies and larval-pupal stages and may contribute to integrated pest management tactics. In the laboratory, neem oil-treated fruit had the same number of landings and time spent on treated fruit as the control but showed reduced pupal development. Females selected kaolin-treated fruits for landing less often, with reduced pupal development. Soil treatment with neem cake and neem seed powder reduced pupal survival. In the field, neem treatment had a greater number of infested fruits and greater pupal development than the control, but fewer flies emerged. Kaolin was not different from the control in percent of infested fruits or pupal development, but fewer flies emerged. Neem cake and neem seed powder were found to lose efficacy in the field.

Keywords: integrated pest management, stone fruits, neem, kaolin, West Africa
Arrival of Oriental Fruit Fly in West Africa and Its Impact

Mango (Mangifera indica L., Anacardiaceae), native to the IndoBurma region, was introduced to Senegal in 1824 (Rey et al. 2006). The Niayes zone (northwestern Senegal) and Casamance region (southern Senegal, below Gambia) are the localities in Senegal where mango is mostly grown (Mbaye 2006). The mango supply chain generates many jobs from production, to harvest, to postharvest (Colen et al. 2012). Mango production is for both domestic consumption and for export markets. Senegal is the second largest mango exporter to European Union countries among the Economic Community of West African States (ITC 2015). However, an economic and quarantine tephritid fruit fly, the oriental fruit fly, Bactrocera dorsalis Hendel (formerly Bactrocera invadens Drew, Tsuruta, and White), entered Senegal in 2004 (Vayssières et al. 2011) and caused severe losses in fruit production (up to $80 \%$ ) (Ternoy et al. 2006).

Native to Asia, B. dorsalis is widespread in Asia, Africa, and Hawaii. It is a generalist species, which attacks at least 34 species of fruit tree including 24 varieties of mango in Senegal (Ndiaye et al. 2012) and could infest more than 300 species of fruits and

${ }^{\dagger}$ Corresponding author: D. G. Pfeiffer; E-mail: dgpfeiff@vt.edu

Funding: This work was made possible by USAID/ERA (Education, Research in Agriculture) cooperative agreement 685-A-00-10-00194-306 00.

The author(s) declare no conflict of interest.

(C) 2019 The American Phytopathological Society vegetables (Plant Health Australia 2018). Tactics used to control $B$. dorsalis populations in Senegal are mass trapping, bait treatment with spinosad, and release of parasitoids (Fopius arisanus Sona, Hymenoptera: Braconidae) (Ndiaye et al. 2015). However, these tactics are too expensive and do not cover all mango production zones.

Neem, Azadirachta indica Juss. (Meliaceae), native to India, is grown in tropical and subtropical areas of Africa, America, and Australia (Schmutterer 1990). Neem has an active ingredient, azadirachtin, which has been found to have multiple modes of action affecting the behavior and physiology of insect pests. Azadirachtin is an insect growth regulator (ecdysis inhibitor), feeding deterrent, repellent, ovicide, and inhibitor of fecundity (Ascher 1993; Mordue (Luntz) et al. 2000). Neem products were found to decrease female oviposition, pupal survival, and adult longevity (Böckmann et al. 2014; Di Ilio et al. 1999; Silva et al. 2013; Singh and Singh 1998; Stark et al. 1990).

Kaolin is a natural clay mineral from weathering of aluminous minerals (ATTRA 2004). Nontoxic, kaolin is used in food processing, in cosmetics, and in health products (Rasad and Rangeshwaran 2000). In pest management, when kaolin is sprayed on crops it forms a white particle barrier that protects the crops from heat stress and pests settling, laying eggs, and feeding (Glenn and Puterka 2005). Surround WP (Tessenderlo Kerley, U.S.A.) is made of $95 \%$ kaolin clay and $5 \%$ inactive ingredients. Leskey et al. (2010) found that Surround WP was a deterrent, a repellent, and an insecticide of apple maggot, Rhagoletis pomonella Walsh (Diptera: Tephritidae). Surround WP prevented medfly, 
Ceratitis capitata Wiedemann, infestation on citrus and resulting decay of fruits (D'Aquino et al. 2011). Surround WP is as effective as spinosad (a spinosyn) and azinphos-methyl (an organophosphate) on apple maggot infestation (Villanueva and Walgenbach 2007).

The aims of this research were to (i) determine the effect of neem oil and kaolin on the behavior and reproduction of B. dorsalis and (ii) determine the effect of soil treatment with neem cake and neem seed powder on the survival of the larval and pupal stages of $B$. dorsalis. Research to address these objectives was conducted in the laboratory and in the field.

\section{Effect of Foliar and Fruit Treatment with Neem Oil and} Kaolin in Behavior and Reproduction of $B$. dorsalis

Laboratory study. Experiments were conducted in the Entomology Laboratory at the Direction de la Protection des Végétaux (DPV) in Dakar, Senegal. Two products were used: Neemland oil and Surround WP. Neemland oil (95\% neem oil and 5\% neem soap) was produced locally in Senegal by Neemland Ecosystem SARL. Neem oil solution was made from $2 \mathrm{ml}$ of Neemland oil mixed with $200 \mathrm{ml}$ of water according to the label rate $(10 \mathrm{ml}$ of neem oil per liter of water). Surround WP (95\% kaolin and 5\% other ingredients) was obtained from Tessenderlo Kerley. A kaolin suspension was made from $4.19 \mathrm{~g}$ of Surround WP mixed with $100 \mathrm{ml}$ of water (label rate: 25 to $50 \mathrm{lb}$ per 100 gal of water). An adjuvant, a wetting agent from Niayes Sarraut Dakar Company, helped kaolin to adhere to the surface of mango fruits. Mango fruits were purchased at the market, and three per treatment were treated with either neem oil or kaolin or were left untreated. Two to three applications were made to ensure that the entire surface of the mango fruit was covered with neem oil or kaolin, followed by a 1-h drying time.

Three groups of 10 gravid females were placed into separate cages $(30 \times 30 \times 30 \mathrm{~cm})$, one group per cage, the day before the trial $(24 \mathrm{~h})$ to acclimate. One mango from each of the three treatments (neem oil, kaolin, and control) was placed into each of the cages using a $3 \times 3$ Latin square design so that each mango treatment combination was located at each of three positions in the cages. The design was replicated five times, resulting in 15 mangoes tested per treatment. Immediately after placing treated mangoes in each cage, the behavior of females was video recorded with a digital camera (Panasonic, DMC-TS6) for a period of $5 \mathrm{~min}$. The number of landings and time spent on each fruit were recorded. Mangoes were removed from cages after $48 \mathrm{~h}$ and incubated individually in containers filled with sand for pupation.

After 2 weeks, the number of pupae per mango for each treatment was recorded. The number of landings, time spent on fruit, and number of pupae were log transformed to homogenize the variance and to satisfy the assumption of normality for the analysis. An analysis of variance (ANOVA) was carried out to test for significant differences between the treatments in the mean number of landings and mean number of pupae. Data on time spent by adult $B$. dorsalis on mango fruit were analyzed using an analysis of covariance (ANCOVA) with the number of landings as a covariate. Post hoc multiple comparison of the mean responses among treatments was carried out using Tukey-Kramer HSD (Zar 2010). All analyses were carried out with JMP Pro 11 (SAS Institute, Cary, NC) at a significance level of $\alpha=0.05$.

The result of analysis of the data from the laboratory bioassay showed that at least one of the treatments, kaolin, neem, and untreated control, had a significant effect on the mean number of female $B$. dorsalis landing on mangoes $(F=4.4157, \mathrm{df}=2,38, P=$ 0.019). Post hoc comparison showed that the significant treatment effect resulted from the lower mean number of female landings on kaolin-treated mangoes compared with the control (Fig. 1). A significant difference was also observed among treatments with respect to the time spent by adult female flies on mangoes $(F=$ 5.5293, $\mathrm{df}=2,35, P=0.008$ ). Adult females spent significantly less time on kaolin-treated mangoes compared with neem-treated and control mangoes (Fig. 2). The mean numbers of pupating larvae were also significantly affected by treatment $(F=26.3372$,

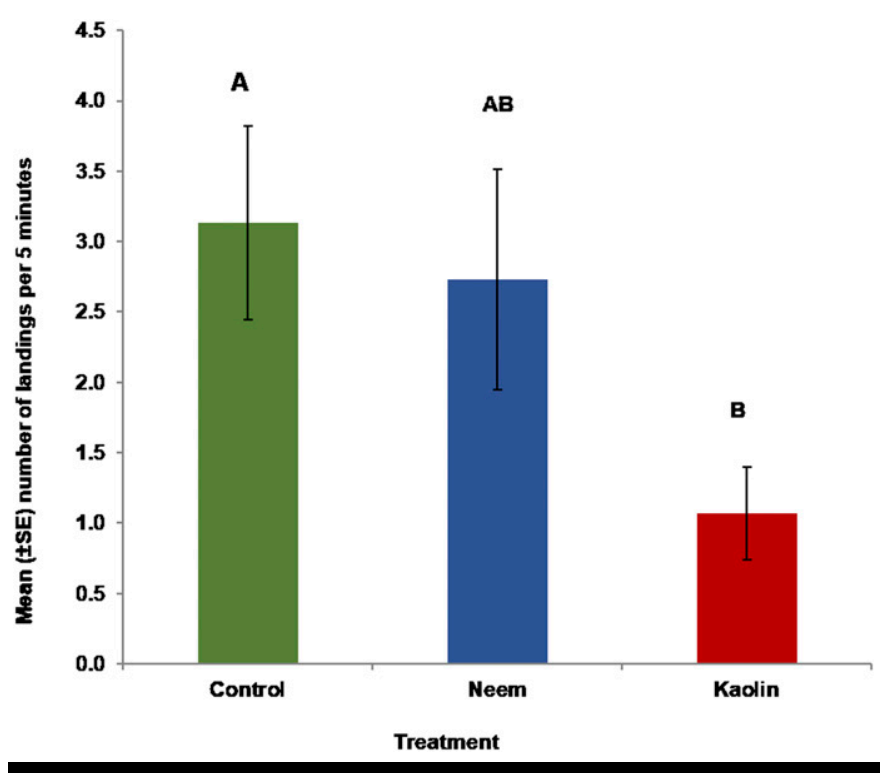

FIGURE 1

Mean $( \pm \mathrm{SE})$ number of landings by Bactrocera dorsalis on untreated and treated mango fruit for 5 min observation in cage assays ( $n=15$, Latin square ANOVA). Bars with different letters denote significant differences at $F=$ 4.4157, $\mathrm{df}=2,38, P=0.019$.

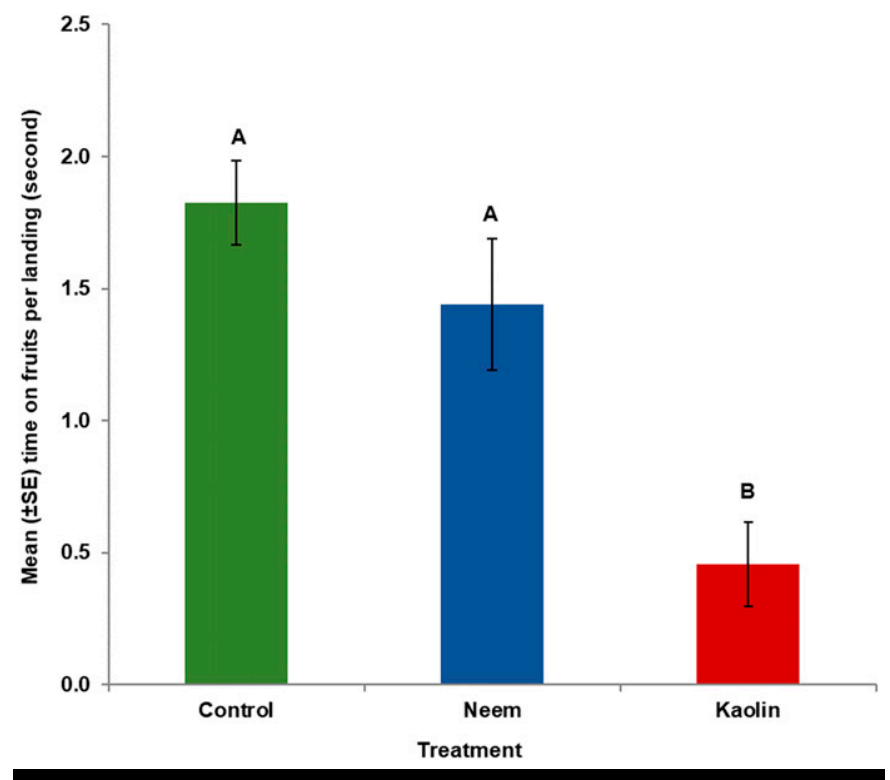

FIGURE 2

Mean ( \pm SE) time spent by Bactrocera dorsalis on untreated and treated mango fruit with neem oil and kaolin per landing in cage assays $(n=15$, Latin square ANCOVA). Bars with different letters denote significant differences at $F=5.5293, \mathrm{df}=2,35, P=0.008$. 
df $=2,32, P<0.0001$ ), with a lower mean number of pupae emerging from neem- and kaolin-treated mangoes compared with the control (Fig. 3).

Field study. Field experiments were conducted in Niayes and at Djibelor Village in Casamance. Three orchards were selected at each of the two localities. In Niayes, orchards' GPS locations were $14.953 \mathrm{~N} 17.032 \mathrm{~W}, 14.972 \mathrm{~N} 17.004 \mathrm{~W}$, and $14.986 \mathrm{~N} 17.005 \mathrm{~W}$, and in Djibelor, orchards' GPS locations were $12.550 \mathrm{~N} 16.321 \mathrm{~W}$, $12.556 \mathrm{~N} 16.322 \mathrm{~W}$, and $12.554 \mathrm{~N} 16.320 \mathrm{~W}$. Four trees were selected for testing within each orchard. Each of the selected trees was divided into three treatment zones around the tree canopy, with each zone separated by an untreated buffer. The treatment zones were randomly assigned to one of three treatments: neem oil, kaolin, or untreated control.

Two applications of neem oil and kaolin were applied at 2-week intervals at label rates using hand-pumped backpack sprayers. Two weeks after the second application, 10 mango fruits were randomly selected and harvested from each treatment zone of the four test trees in each orchard and placed in a tagged plastic bag. The mango fruits collected from each of the 36 treatment zones ( 3 zones/tree $\times 4$ trees/orchard $\times 3$ orchards) were incubated in 15-liter buckets quarter-filled with sand to collect pupae. Each bucket was covered with a transparent fabric to prevent escape of emerged flies. Three weeks later, the buckets were examined to determine the percent of mango fruits infested by $B$. dorsalis, the numbers of pupae, and the number of emerged adults in each of the treatment groups.

No mangoes from any of the treatment groups from the orchards at Niayes were infested by $B$. dorsalis. Therefore, only data from the mangoes collected at the three orchards at Djibelor Village, Casamance, were analyzed. Data on the percent of infested mangoes and number of pupae were analyzed using a mixed-model ANOVA with mango tree nested within orchard as a random effect. Post hoc multiple comparison of the mean responses among treatments was carried out using Tukey-Kramer HSD (Zar 2010). $\chi^{2}$ analysis was used to test for significant differences in the percent of $B$. dorsalis adults emerging from pupae collected from each of

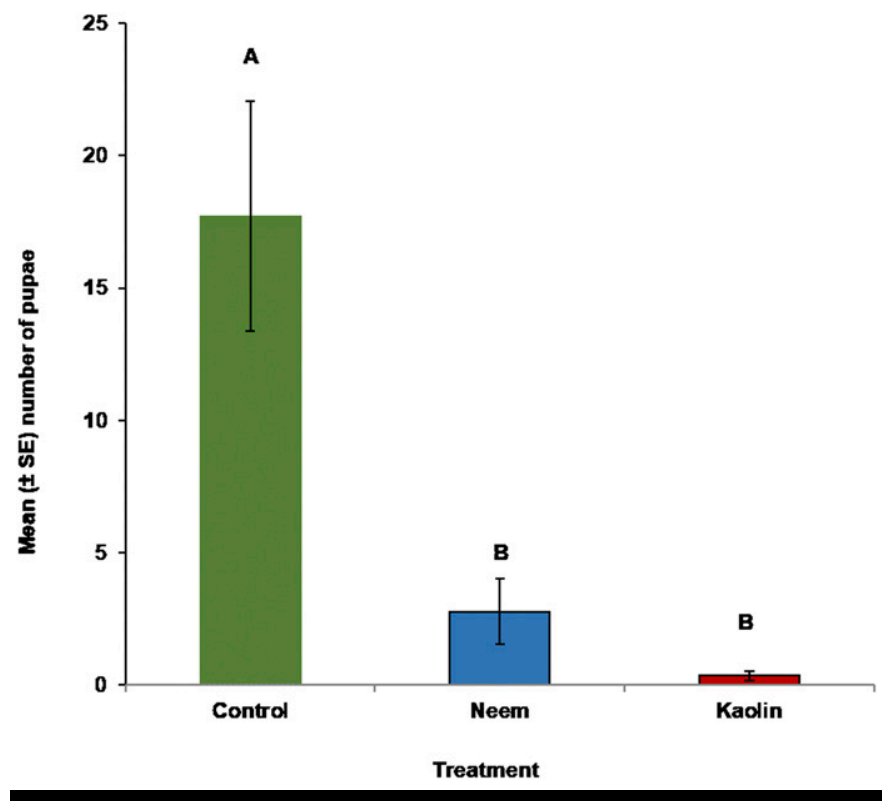

FIGURE 3

Mean $( \pm$ SE) number of Bactrocera dorsalis pupae per untreated and treated mango fruit in cage assays ( $n=15$, Latin square ANOVA). Bars with different letters denote significant differences at $F=26.3372$, df $=2,32, P<0.0001$. the three treatments. For this analysis, orchard was considered a blocking factor. All analyses were carried out with JMP Pro 11 (SAS Institute) at a significance level of $\alpha=0.05$.

The percent of mangoes infested with $B$. dorsalis differed significantly among the three treatments: neem, kaolin, and untreated control $(F=3.6014$, df $=2,22, P=0.044)$. The mean percent of mangoes infested in the kaolin treatment did not differ significantly from either the control or neem treatments; however, the mean percent of infested mangoes in the neem treatment was significantly greater than in the control (Fig. 4). Further, the analysis showed that the mean number of pupae differed significantly among the three treatments $(F=4.0958, \mathrm{df}=2,22, P=0.031)$, with a significantly greater number of pupae observed in the neem treatment compared with the control and kaolin treatments (Fig. 5). The analysis also determined that there was a significant difference among the three treatments in the percent of adults that emerged from pupae $\left(\chi^{2}=\right.$ 83.128 , df $=2, P<0.0001)$. A significantly higher percentage of flies emerged from the control treatment compared with both the neem and kaolin treatments (Fig. 6).

Neem oil did not repel or deter oviposition by B. dorsalis. Females of $B$. dorsalis landed and laid eggs on neem-treated mango fruits. The repellent and deterrent effect of azadirachtin (Ascher 1993; Mordue (Luntz) et al. 2000) was not evident in this study. Neem toxicity may vary among species even within the same family. Stark et al. (1990) found B. dorsalis was less sensitive than the melon fly, Bactrocera cucurbitae Coquillett (Diptera: Tephritidae), to neem oil. The repellency of neem is related to the concentration of neem in the formulation (González-Gómez et al. 2012). Low concentrations of neem were shown to not prevent bee pupae from becoming infested by Varroa destructor Anderson and Trueman (Acari: Varroidae). Vanranden and Roitberg (1998) reported that neem insecticide did not act as an ovipositional deterrent for the western cherry fruit fly, Rhagoletis indifferens Curran (Diptera: Tephritidae), under laboratory conditions. However, the mean numbers of pupating larvae were significantly lower on neemtreated mangoes compared with the control in our study. The number of eggs that hatched decreased when females of the peach

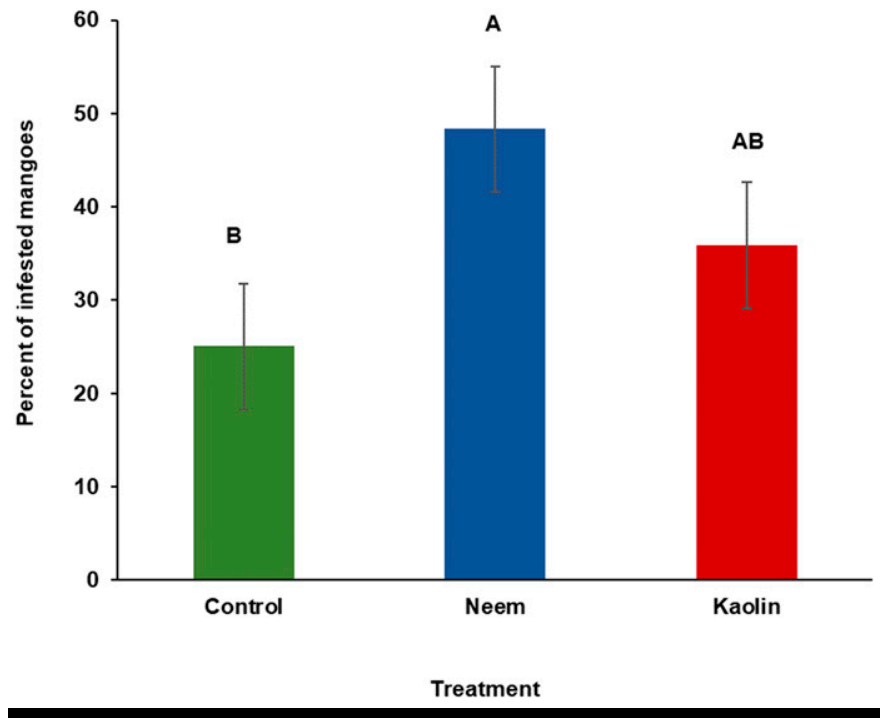

FIGURE 4

Percent of infested mango fruits treated with neem and kaolin, compared with untreated control (Djibelor field, $n=120$, mixed model ANOVA). Bars with different letters denote significant differences at $F=3.6014$, $\mathrm{df}=2,22$, $P=0.044$. 
fruit fly, Bactrocera zonata Saunders (Diptera: Tephritidae), laid eggs on neem-treated fruits (Mahmoud and Shoeib 2008). Their laboratory results support our laboratory and field results, in which the number of pupae and the number of emerged flies, respectively, were significantly lower on neem-treated fruit compared with the control (Figs. 3 and 6). Vijayalakshmi et al. (2014) reported that efficacy of neem oil depends on the source of manufacture and doses. In addition, they found that neem oil was less efficient in the field than in the laboratory.

Surround WP discouraged female $B$. dorsalis from landing and ovipositing on treated fruits in our laboratory conditions. When the

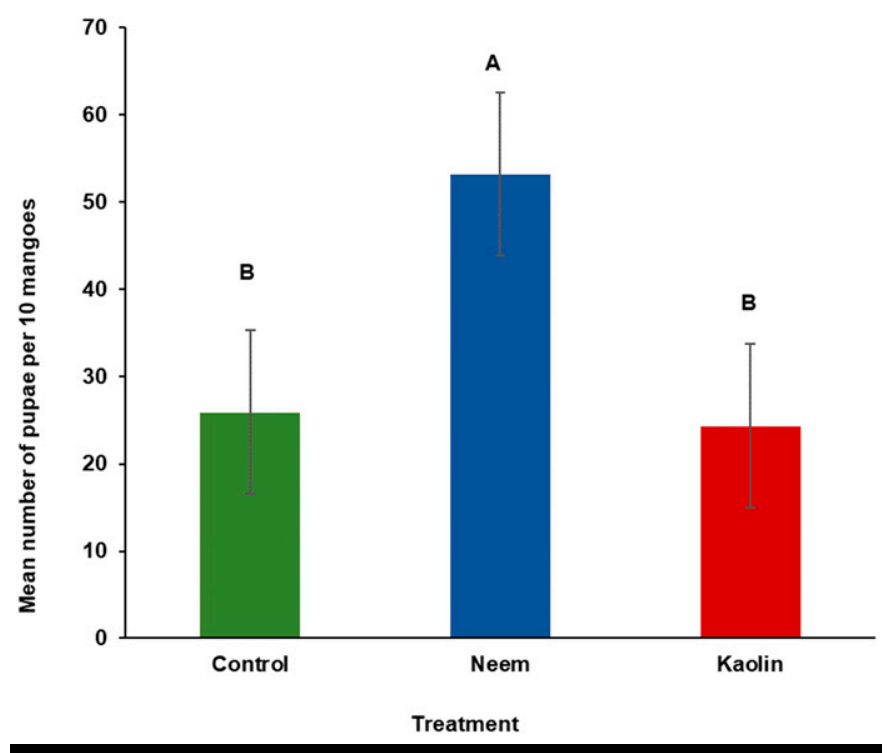

FIGURE 5

Mean $( \pm \mathrm{SE}$ ) number of Bactrocera dorsalis pupae in 10 mango fruits per treatment (Djibelor field, $n=120$, mixed model ANOVA). Bars with different letters denote significant differences at $F=4.0958, \mathrm{df}=2,22, P=0.031$.

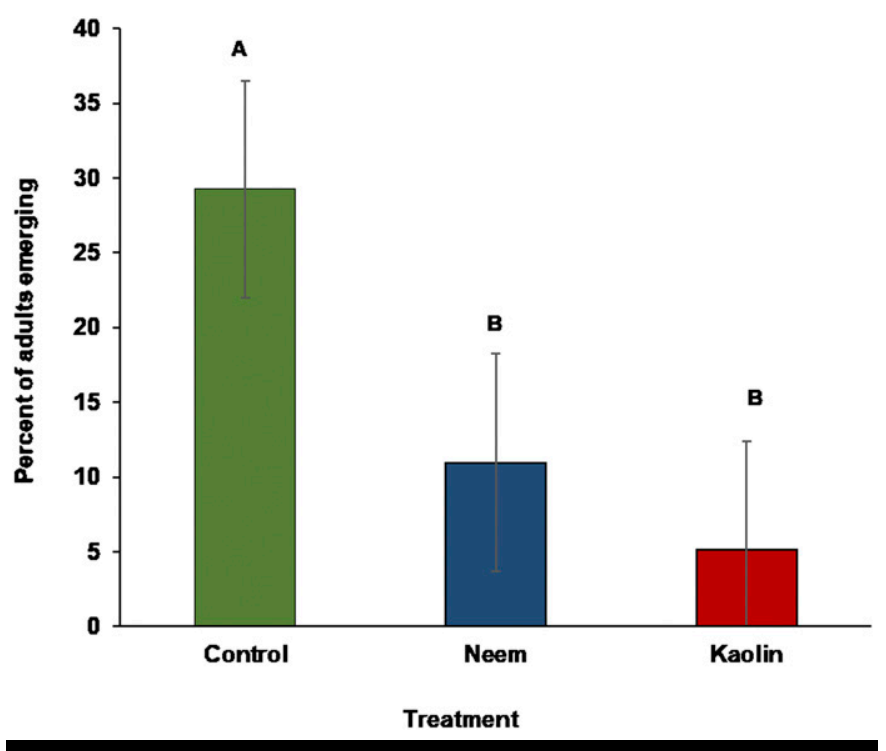

FIGURE 6

Percent of adults emerging in treated and untreated mango fruit (Djibelor field, $n=120, \chi^{2}$ analysis). Bars with different letters denote significant differences at $P<0.001$.
Surround WP was sprayed on fruit, the white coating from kaolin diminished visual attractiveness and served as a tactile deterrent. However, kaolin has shown variable efficacy among other tephritids. Leskey et al. (2010) observed that apple maggot, Rhagoletis pomonella Walsh (Diptera: Tephritidae), spent less time on kaolintreated fruit relative to untreated fruit. However, the efficacy of Surround WP (kaolin) was found to decrease in high $R$. pomonella populations. Likewise, in this current field study, efficacy of Surround WP decreased. Lo Verde et al. (2011) found that infestation by the Mediterranean fruit fly, Ceratitis capitata Wiedemann (Diptera: Tephritidae), was not significantly different in kaolin-treated versus untreated clementines at high pest densities and when there were no host plants besides clementine.

\section{Effect of Soil Treatment with Neem Cake and Neem Seed Powder on Survival and Development of the Larval and Pupal Stages of $B$. dorsalis}

Neem products used in this study were neem seed cake (Neemland Rakkal) and neem seed powder (Neemland Sol). Both products were locally manufactured by Neemland Ecosystem Company in Senegal. Neem cake is the solid waste of pressed seed after oil extraction, it differs from neem seed powder by the absence of oil. Label rates were 30 to $50 \mathrm{~g} /$ plant or 50 to $100 \mathrm{~g} / \mathrm{m}^{2}$ (field) for neem seed cake and $10 \mathrm{~g} /$ plant or $100 \mathrm{~g} / \mathrm{m}^{2}$ (field) for neem seed powder.

Laboratory study. This study was conducted at the Entomology Laboratory of DPV, Dakar. Three treatments (neem seed cake, neem seed powder, and an untreated control) were used to assess the effect of neem products on the survival of larvae and pupae of $B$. dorsalis. Soil samples treated with either neem seed cake or neem seed powder were compared with untreated soil. Soil (30 g) was mixed with either $30 \mathrm{~g}$ of neem seed cake or $10 \mathrm{~g}$ of neem seed powder. Each replicate consisted of one treatment container (either neem seed cake or neem seed powder) and an untreated container (control). A group of 17 randomly selected third-instar larvae was placed in each container, and treatments were replicated six times. Containers were covered with a transparent fabric to prevent escape of larvae or emerged flies. Two weeks later, the percent of emerged flies was recorded.

A $\chi^{2}$ analysis was used to determine whether there were significant differences in the percent of emerged $B$. dorsalis adults among the three treatments. All analyses were carried out with JMP Pro 11 (SAS Institute) at a significance level of $\alpha=0.05$.

Neither neem seed cake nor neem seed powder significantly decreased $B$. dorsalis larval development into pupae. All of the larvae in the three treatments developed to the pupal stage. Neem seed cake and neem seed powder, however, significantly decreased the percent of pupal survival, and few adult flies emerged compared with the control $\left(\chi^{2}=262.5, \mathrm{df}=2, P<0.0001\right.$; Fig. 7). Pupae that did not result in adults when expected were kept under observation for late-emerging adults, which did not appear.

Field study. This study was conducted in a mango orchard at Djibelor (Casamance) and at DPV (Dakar) after mango fruit season to ensure that there were no pupae in the soil. At each of the two localities, emergence cages $(50 \times 50 \times 50 \mathrm{~cm})$ were installed under three mango trees to test the effect of neem seed cake and neem seed powder on the survival of the oriental fruit fly larvae and pupae. Pupal survival was measured by adult emergence. Cages were covered with a black fabric, and a transparent bottle was inserted at the top of the cage so that, at emergence, flies followed the light and were captured in the bottle. Three cages, one for each treatment (neem seed cake, neem seed powder, or untreated control) were placed randomly in the shade under a randomly selected mango 
tree. Each cage was placed into a hole dug under the tree, and the bottom $10 \mathrm{~cm}$ of the cage was filled with the soil that had been removed from the hole. At the top of the soil within one of the cages, $100 \mathrm{~g}$ of neem seed cake ( $4 \times$ field label rate) was poured and mixed gently. This rate was used to be conservative, because this was a new method of application, in an area of high oriental fruit fly pressure. If successful, we could try different rates in a subsequent study. Likewise, $100 \mathrm{~g}$ of neem seed powder (4× field label rate) was poured onto the top of the soil inside another cage and mixed gently. The soil inside the third cage was stirred and left untreated to serve as a control. At the laboratory at DPV, uninfested mangoes were placed into cages with gravid $B$. dorsalis females for $48 \mathrm{~h}$. The following day, three mango fruits were randomly selected and placed in each of the three emergence cages located under each of the mango trees. After 10 days, emerged fruit flies were collected daily over a 2 -week period.

A nonparametric Wilcoxon rank sums test (Zar 2010) was used to test for significant differences in the number of emerged $B$. dorsalis adults among the three treatments at the two localities. For the initial analysis, locality was considered a blocking factor. However, because the analysis showed that locality was not significant, subsequent analyses were conducted separately for each locality used in the experiment. All analyses were carried out with JMP Pro 11 (SAS Institute) at a significance level of $\alpha=0.05$.

Results showed that there were no significant differences in emergence of $B$. dorsalis adults between untreated soil and soil treated with neem seed cake or neem seed $\operatorname{powder}\left(\chi^{2}=1.065, \mathrm{df}=2\right.$, $P>0.05)$. There were also no significant differences among the treatments in the emergence of adult flies at either of the two study locations (Fig. 8).

In our laboratory study, neem seed cake and neem seed powder did not prevent larvae from developing into pupae. However, they significantly decreased the percent of pupal survival, and few adult flies emerged compared with the control. Neem cake has a larvicidal

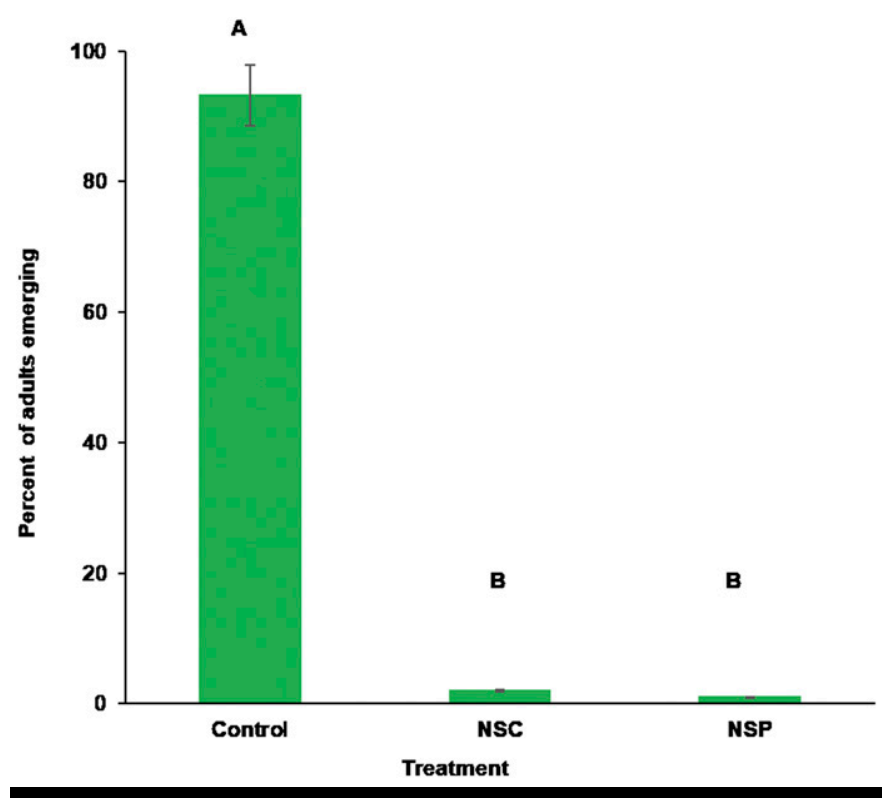

\section{FIGURE 7}

Effect in the laboratory of soil treated with neem seed cake (NSC) or neem seed powder (NSP) and untreated soil (control) on number of emerged Bactrocera dorsalis ( $n=102$ larvae, $\chi^{2}$ analysis). Bars with different letters denote significant differences with $\chi^{2}=262.5, \mathrm{df}=2, P<0.0001$. Lines denote standard error. effect on some Diptera such as Aedes albopictus (Stegomyia albopicta) (Diptera: Culicidae) because of salannin, an active ingredient different from azadirachtin (Nicoletti et al. 2012). Regardless of toxicant, in our study, neem cake did not have a larvicidal effect on $B$ dorsalis. Silva et al. (2011) found that neem cake did not affect the development of Mediterranean fruit fly larvae to pupae but caused pupal mortality. Pupal mortality was $100 \%$ for mixtures higher or equal to $75 \%$ in the neem cake. Singh (2003) found that neem seed kernel extract significantly decreased the percent of emerged oriental fruit flies, and Stark et al. (1990) showed that emergence of oriental fruit fly, melon fly, and Mediterranean fruit fly adults was decreased in sand treated with neem seed extracts. These results support our laboratory results, in which all of the larvae in the three treatments developed to the pupal stage and percent of $B$. dorsalis adults was significantly decreased in neem seed cake and neem seed powder treatments compared with the control (Fig. 7).

In the field, neem seed cake and neem seed powder did not affect survival of emerged flies. There were no significant differences among the treatments in the emergence of adult flies. Weaver ants, Oecophylla longinoda Latreille (Hymenoptera: Formicidae), were observed in control cages but not in the treated cages at Djibelor field. Weaver ants were not observed in any cages at Dakar. Weaver ants are predators of larvae and adults of B. dorsalis and other tephritid fruit flies on mango (Vayssières et al. 2016). Diamé et al. (2015), for example, found low populations of $B$. dorsalis in mango orchards in the presence of weaver ant colonies. Neem was found to be a repellent to red ants, Oecophylla smaragdina Fabr. (Formicidae: Formicinae), by Vishwakarma et al. (2012). Perhaps, in the current

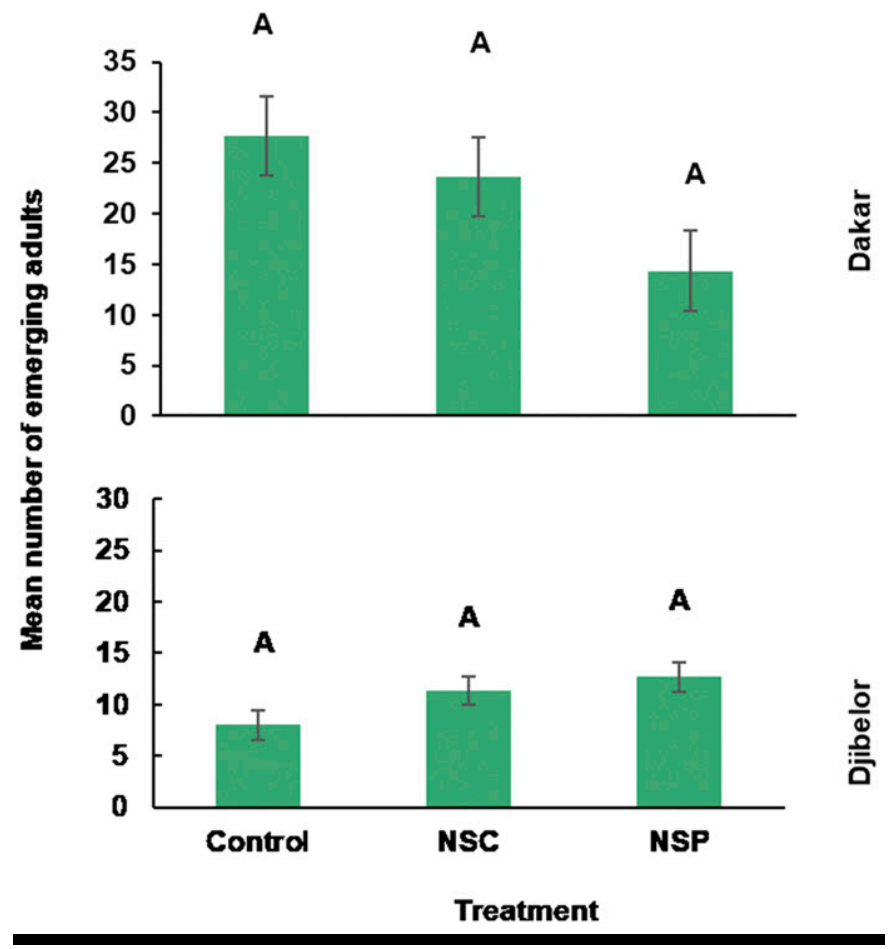

FIGURE 8

Effect in the field (Dakar and Djibelor) of soil treated with neem seed cake (NSC) or neem seed powder (NSP) and untreated soil (control) on number of emerged Bactrocera dorsalis. Data were analyzed using a nonparametric Wilcoxon rank sums test. Means with different letters denote significant differences at $\alpha=0.05$. Lines denote standard error. 
study, cages treated with neem seed cake and neem seed powder discouraged predation of emerged flies by weaver ants. Although we did not observe ants in the Dakar trial, it is still possible that there was predation on larvae and emerged flies by ants, especially because the laboratory colony of fruit fly at DPV was attacked by weaver ants in 2014 and 2015. The effect of sunlight on the neem product also needs to be considered. Vijayalakshmi et al. (2014), for example, reported a rapid decrease of neem efficacy in the field owing to sunlight. Therefore, it is possible that despite the placement of cages under the shade of mango trees, the efficacy of the neem products used in this study was affected by sunlight.

\section{Conclusion}

Laboratory and field experiments on foliage and fruit showed that neem oil and kaolin could decrease infestation and populations of the oriental fruit fly. However, work remains to be done to make field applications effective. In the future, neem oil and kaolin field trials should be repeated with different test conditions to determine the best treatments and treatment frequency that will negatively affect oriental fruit fly behavior and development. Research may focus on the optimal intervals between applications in the field. A benefit of using these products is that applications can be made until shortly before harvest if needed.

The laboratory soil treatment showed that neem seed cake and neem seed powder could be promising organic insecticides to manage oriental fruit fly populations while in the soil. This would aid in control independent of tree size, unlike foliar treatments. Future research may focus on the efficacy of neem seed cake and neem seed powder in the field by excluding ants, the effect of neem seed cake and neem seed powder on weaver ants, the effect of temperature and sunlight on efficacy of neem seed cake and neem seed powder, and the number of applications of neem seed cake and neem seed powder that would cause a decrease of emerged flies in the field.

Surround WP, neem oil, neem seed cake, and neem seed powder are harmless organic insecticides that should be added to the integrated pest management tools for $B$. dorsalis in order to avoid pest resistance and chemical residue in soil, to protect natural enemies, and to manage immature and adult stages of $B$. dorsalis.

\section{Acknowledgments}

We thank Emile V. Coly, Kemo Badji, Kalilou Bodiang, Eladji Omar Dieng, and Saliou Djiba for their support with laboratory and fieldwork. We thank Lamine Diouf for his help on the laboratory work in Thies and all mango orchard owners that allowed us to conduct field trials.

\section{Literature Cited}

Ascher, K. R. S. 1993. Nonconventional insecticidal effects of pesticides available from the neem tree, Azadirachta indica. Arch. Insect Biochem. Physiol. 22:433-449.

ATTRA. 2004. Kaolin clay for management of glassy-winged sharpshooter in grapes. https://www.slideshare.net/ElisaMendelsohn/kaolin-clay-formanagement-of-glassywinged-sharpshooter-in-grapes.

Böckmann, E., Koppler, K., Hummel, E., and Vogt, H. 2014. Bait spray for control of European cherry fruit fly: An appraisal based on semi-field and field studies. Pest Manag. Sci. 70:502-509.

Colen, L., Maertens, M., and Swinnen, J. 2012. Private standards, trade and poverty: GlobalGAP and horticultural employment in Senegal. World Econ. 35:1073-1088.

D’Aquino, S., Cocco, A., Ortu, S., and Schirra, M. 2011. Effects of kaolinbased particle film to control Ceratitis capitata (Diptera: Tephritidae) infestations and postharvest decay in citrus and stone fruit. Crop Prot. 30: 1079-1086.

Di Ilio, V., Cristofaro, M., Marchini, D., Nobili, P., and Dallai, R. 1999. Effects of a neem compound on the fecundity and longevity of Ceratitis capitata (Diptera: Tephritidae). J. Econ. Entomol. 92:76-82.
Diamé, L., Grechi, I., Rey, J. Y., Sané, C. A. B., Diatta, P., Vayssières, J. F., Yasmine, A., Bon, H. D., and Diarra, K. 2015. Influence of Oecophylla longinoda Latreille, 1802 (Hymenoptera: Formicidae) on mango infestation by Bactrocera dorsalis (Hendel) (Diptera: Tephritidae) in relation to Senegalese orchard design and management practices. Afr. Entomol. 23:294-305.

Glenn, D. M., and Puterka, G. J. 2005. Particle films: A new technology for agriculture. Hortic. Rev. (Am. Soc. Hortic. Sci.) 31:1-44.

González-Gómez, R., Otero-Colina, G., Villanueva-Jiménez, J. A., Peña-Valdivia, C. B., and Santizo-Rincón, J. A. 2012. Repellency of the oily extract of neem seeds (Azadirachta indica) against Varroa destructor (Acari: Varroidae). Exp. Appl. Acarol. 56:261-270.

ITC. 2015. Mango from Senegal, summer flavor. http://www.intracen.org.

Leskey, T. C., Wright, S. E., Glenn, D. M., and Puterka, G. J. 2010. Effect of Surround WP on behavior and mortality of apple maggot (Diptera: Tephritidae). J. Econ. Entomol. 103:394-401.

Lo Verde, G., Caleca, V., and Lo Verde, V. 2011. The use of kaolin to control Ceratitis capitata in organic citrus groves. Bull. Insectol. 64: 127-134.

Mahmoud, M. F., and Shoeib, M. A. 2008. Sterilant and oviposition deterrent activity of neem formulation on peach fruit fly Bactrocera zonata (Saunders) (Diptera: Tephritidae). J. Biopesticides 1:177-181.

Mbaye, N. 2006. Inventaire et caractérisation des champignons phytopathogènes responsables de maladies post-récoltes chez deux variétés de mangues (Mangifera indica L.), Kent et Keitt, destinées à l'exportation dans la zone des Niayes du Sénégal. Dissertation, Cheikh Anta Diop University, Dakar, Senegal.

Mordue (Luntz), A. J., and Nisbet, A. J. 2000. Azadirachtin from the neem tree Azadirachta indica: Its action against insects. An. Soc. Entomol. Brasil 29: 615-632.

Ndiaye, O., Ndiaye, S., Djiba, S., Ba, C. T., Vaughan, L., Rey, J.-Y., and Vayssières, J.-F. 2015. Preliminary surveys after release of the fruit fly parasitoid Fopius arisanus Sonan (Hymenoptera Braconidae) in mango production systems in Casamance (Senegal). Fruits 70:91-99.

Ndiaye, O., Vayssieres, J.-F., Yves Rey, J., Ndiaye, S., Diedhiou, P. M., Ba, C. T., and Diatta, P. 2012. Seasonality and range of fruit fly (Diptera: Tephritidae) host plants in orchards in Niayes and the Thiès Plateau (Senegal). Fruits 67:311-331.

Nicoletti, M., Mariani, S., Maccioni, O., Coccioletti, T., and Murugan, K. 2012. Neem cake: Chemical composition and larvicidal activity on Asian tiger mosquito. Parasitol. Res. 111:205-213.

Plant Health Australia. 2018. The Australian Handbook for the Identification of Fruit Flies. Version 3.1. Plant Health Australia, Canberra, Australia.

Rasad, R. D., and Rangeshwaran, R. 2000. Shelf life and bioefficacy of Trichoderma harzianum formulated in various carrier materials. Plant Dis. Res. 15: 38-42.

Rey, J.-Y., Diallo, T. M., Vannière, H., Didier, C., Kéita, S., and Sangaré, M. 2006. The mango in French-speaking West Africa. Fruits 61:281-289.

Schmutterer, H. 1990. Properties and potential of natural pesticides from the neem tree, Azadirachta indica. Annu. Rev. Entomol. 35:271-297.

Silva, M. A., Alvarenga, C. D., Bezerra-Silva, G. C. D., Mastrangelo, T., LopesMielezrski, G. N., and Giustolin, T. 2011. Toxic effects of neem seed cake on the larval-pupal (prepupal) stage of Mediterranean fruit fly (Diptera: Tephritidae). Fruits 66:363-369.

Silva, M. A., Bezerra-Silva, G. C. D., Vendramim, J. D., and Mastrangelo, T. 2013. Sublethal effect of neem extract on Mediterranean fruit fly adults. Rev. Bras. Frutic. 35:93-101.

Singh, S. 2003. Effects of aqueous extract of neem seed kernel and azadirachtin on the fecundity, fertility and post embryonic development of the melonfly, Bactrocera cucurbitae and the oriental fruit fly, Bactrocera dorsalis (Diptera: Tephritidae). J. Appl. Entomol. 127:540-547.

Singh, S., and Singh, R. P. 1998. Neem (Azadirachta indica) seed kernel extracts and azadirachtin as oviposition deterrents against the melon fly (Bactrocera cucurbitae) and the oriental fruit fly (Bactrocera dorsalis). Phytoparasitica 26:191-197.

Stark, J. D., Vargas, R. I., and Thalman, R. K. 1990. Azadirachtin: Effects on metamorphosis, longevity, and reproduction of three tephritid fruit fly species (Diptera: Tephritidae). J. Econ. Entomol. 83:2168-2174.

Ternoy, J., Poublanc, C., Diop, M., and Nugawela, P. 2006. Mango value chain-Senegal: Analysis and strategic framework for sub-sector growth initiatives, pp. 1-90. United States Agency for International Development, SAGIC IQC No. 685-I-01-06-00005-00.

Vanranden, E. J., and Roitberg, B. D. 1998. Effect of a neem (Azidirachta indica)-based insecticide on oviposition deterrence, survival, behavior and reproduction of adult western cherry fruit fly (Diptera: Tephritidae). J. Econ. Entomol. 91:123-131. 
Vayssières, J.-F., Offenberg, J., Sinzogan, A., Adandonon, A., Wargui, R., Anato, F., Houngbo, J. Y., Ouagoussounon, I., Diamé, L., Quilici, S., Rey, J.-Y., Goergen, G., De Meyer, M., and Van Mele, P. 2016. The use of weaver ants in the management of fruit flies in Africa. Pages 389-434 in: Fruit Fly Research and Development in Africa-Towards a Sustainable Management Strategy to Improve Horticulture. S. Ekesi, S. A. Mohamed, and M. De Meyer, eds. Springer, Basel, Switzerland.

Vayssières, J.-F., Vannière, H., Gueye, P. S., Barry, O., Hanne, A. M., Korie, S., Niassy, A., Ndiaye, M., and Delhove, G. 2011. Preliminary inventory of fruit fly species (Diptera, Tephritidae) in mango orchards in the Niayes region, Senegal, in 2004. Fruits 66:91-107.
Vijayalakshmi, C. K., Tintumol, K., and Vinodkumar, P. K. 2014. Effect of few commercial neem-based insecticides in the management of coffee berry borer, Hypothenemus hampei Ferrari (Coleoptera: Curculionidae). J. Zool. Stud. 1:22-25.

Villanueva, R. T., and Walgenbach, J. F. 2007. Phenology, management and effects of Surround on behavior of the apple maggot (Diptera: Tephritidae) in North Carolina. Crop Prot. 26:1404-1411.

Vishwakarma, R., Singh, R. P., and Ghatak, S. S. 2012. Bioefficacy of phytochemicals against Vespa orientalis L. and Oecophylla smaragdina F. infesting Apis mellifera L. colony. Indian J. Entomol. 74:82-84.

Zar, J. H. 2010. Biostatistical Analysis, 5th Ed. Pearson Prentice-Hall, Saddle River, NJ. 